Dept. of Surgery 3. Theriogenology,

Faculty of Vet. Med., Alexandria University,

Head of Dept. Prof. Dr. M.Y. Abboud.

\title{
SURGICAL EXPLORATION AND TOPOGRAPHICAL ANATOMY OF THE ABDOMINAL ORGANS IN DONKEYS (With 7 Figs.)
}

\author{
By \\ S.R. NOUH; M.M. KASSEM, M. AMIN*; A.A. KENAWY \\ and A. KARKURA * \\ (Received at 6/1/1992) \\ الاستكثاف الجر احي والتشريحي الطبرغر افي في أعضا.

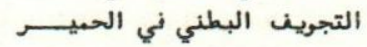

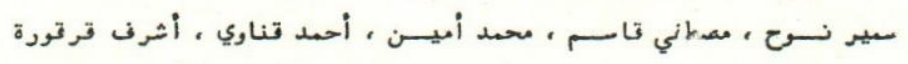

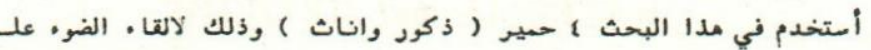

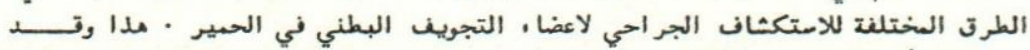

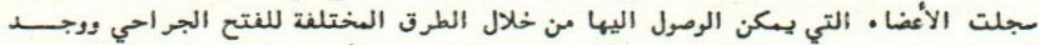

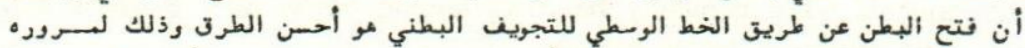

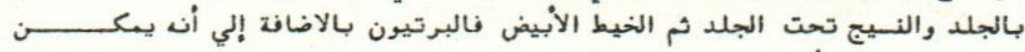

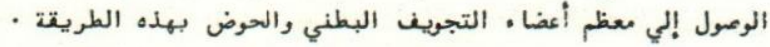

\section{SUMMARY}

Four donkeys of both sexes, two males and two females were used in this study to through light on different methods of surgical exposure of the abdominal organs. The different organs which can be approached through these surgical incisions were enumerated. It was found that the ventral abdominal Midline incision is the incision of choice as it is simple passed only through a vin, subutanous tissues linea alba and peritoneum in addition most of the abdominat and pelvic organs can be well explored.

\section{INTRODUCTION}

The abdomen of the horse may be surgically entered in a number of sites; these sites include, the lateral walls, the ventral wall, the inguinal canals, and through the vagina. The selection of different surgical sites is largely based on the need to make

* Dept. of Anatomy, Faculty of Vet. Med., Alexandria University.

Assiut Vet.Med.J., Vol. 26, No. 52, January 1992. 
the incision as close as possible to the target organ (OEHME and PRIER, 1974; FRANK, 1981; STASHAK, 1987 and TURNER, et al. 1989).

Flank approaches can be done under local infiltration anaesthesia using procain $2 \%$ and tranquilizers such as promazine or acetyle promazine (OEHME and PRIER, 1974). While TURNER, et al. 1989; reported the use of general anaesthesia for ventral midline and inguinal incsions. A good Knowledge of the Topographical anatomy is very important as the anatomical studies on the abdominal and pelvic viscera were descreptive work (NICKLE SHUMMER and SEIFERL, 1973; SISSON, 1975; DYCE SACK and WENSING, 1987). The application of these anatomical facts with surgery must be required (DELAHUTA and HABEL, 1986). The aim of the present work is to through light on the different methods of surgical exposure of the abdominal organs in addition to enumerate the organs which can be easly approached through these approaches.

\section{MATERIAL and METHODS}

The present work was done on four donkeys of both sexes, two males and two females. The animals were clinically healthy ranging between 4-6 years old. The animals were surgically prepared for laparotomy.

The follwing methods of anaesthesia were used for the different surgical incisions:

A ) Flank incisions were done under the effect of local infiltration anaesthesia which was done by deep infiltration along the curve of the last rib and parallel to the ends of the lumbar pracesses as field block using procain $\mathrm{Hcl} 2 \%$ preceeded by comblene as a tranquilizer $10 \mathrm{mg} / 100 \mathrm{~kg}$ bw B.W.

B ) Ventral midline and the inguinal and paramidline incisions were all done in dorsal recumbancy using chloral incisions narcosis in a dose of $5 \mathrm{gm} / 50 \mathrm{~kg}$. b.w. i.v. with combelen $10 \mathrm{mg} / 100 \mathrm{~kg}$ as a tranquilizer.

- Surgical techniques for abdominal incisions.

1 - Flank incision (Right - Left):

20-25 cm skin incision was made midway between the tuber coxa and last rib. The subcutanous tissue and external abdominal oblique muscle were incised in the same direction. The internal oblique abdominal muscle was divided along the direction of its fibers as was the transversus abdominis muscle. The retroperitoneal fat was cleared and the peritoneum was penetrated.

2 - The ventral midline incision:

A) Skin incision starting over the umbalicus nad extended craniad for a distance of $20-25 \mathrm{~cm}$ was made. Following the skin incision, there was a small amount

Assiut Vet.Med.1, Vol. 26, No. 52, January 1992. 


\section{SURGICAL ANATOMY OF THE ABDOMEN}

of $y$ bcutanous tissue and then the linea alba was incised with scalpel the retroperitoneal fat was cleared to reveal the peritoneum with remanant of the round ligament of the liver demarcating the midline. The peritoneum was then opened using the scissors.

\section{3 - Paramidline incision:}

20-25 cm skin incision was made lateral to the midline, then the subcutanous tissue was opened followed by opening of the abdominal muscles (External rectal sheath, rectus adbominis, M.internal rectal sheath and transverse abdominal muscle then the fascia and periton eum were opened using scissors.

\section{4 - Inguinal incision:}

The animal was placed in dorsal recumbancy and inguinal region was prepared for aseptic surgery. $10-15 \mathrm{~cm}$ skin incision was made over the external inguinal ring and was continued through the superficial fascia. The canal was then entered by blunt dissection.

B) Abdominal closure:

The flank laparotomy incision was closed in 5 layers. The peritoneum and transversue abdominis were closed with a layer of simple interrupted sutures using catgut No. 0 the internal oblique abdominal muscle was closed in simple continuous pattern using No. 0 chromic catgut. The external oblique abdominal muscle was also closed in the same manner. The subcutaneous tissue was opposed using catgut 0 and the skin was closed with simple interrupted sutures using silk No. 1. For closure of the ventral midline. The peritoneum was sutured using $2 / 0$ catgut in a continuous pattern. The linea alba was then sutured using ratgut No. $O$ in a simple interrupted manner. The subcutus was closed also using catgut 0 in simple continurous pattern. Then the skin was closed using silk No. 1 in an interrupted manner.

Closure of paramedline incision:

This incision was closed by suturing of the peritoneum using catgut 0 followed by closure of the abdominal muscie using the same suture material in a continuous pattern. This was followed by closure of the subcutus using catgut. The skin was then closed using silk No. 1. Closure of the inguinal incision: The closure of the abdominal incision was done by suturing of the inguinal canal using catgut 0 then suturing of the external inguinalring by the same suture material. The skin was then closed using silk No. 1.

Assiut Vet.Med.J., Vol. 26, No. 52, lanuary 1992. 


\section{S.R. NOUH, et al.}

\section{RESULTS}

The following organs can be approached surgically by the different abdomina! incisions:

\section{Right flank incision:}

Fig. (2) by this approach, exposure of the base of the caecum which provides land marks to locate and examine both the small intestine and colon. The base of the caecum (Fig. 2) was exteriorized and dorsal band (Tenia) located. This band leads to the iliocecal fold, ileocecal junction and ilium. The small intestine is then traced craniad. The junction of the jejunum and duodenum was identified bylocating the duodenocolic ligament which runs from the ascending duodenum to the transverse colon. The duedenum (Fig. 3) cannot be exteriorized surgically but can be palpated as it curves caudally towards and around the misocaecal ligament to become attached to the transverse colon by duodenocolic ligament. The right ventral ascending colon (fig. 4) is connected to the caecum by the caeco-Colic ligament. Both the transverse and descending colon can be expiored by proceedingproximal and distal respectively from duodinocolic ligament. The transverse colon is located just cranial to the cranial mesentric artery and attached to the stomach by the gastrocolic ligament. The pylorus and the liver were approached in the right hypochondrial region. The right kidney was also approached in the sublumbr region. The uterns ovaries in the females, and urinary bladder and accessary genital glands in the males can be appoached in the pelvic cavity.

\section{Left flank incision:}

This incision provided exposure of the left parts of ascending colon and pelvic flexure. The stomach and spleen can be approached. The uterus \& left ovary in females. The left kidney can be approached in the left sublumbar region.

\section{Ventral midline approach Fig. (5):}

By this approach the apex and body of the cecum can be approached which provides a land mark to locate and examine both the small intestine and colon. The cecum was exteriorized by reflecting the apex caudoventrally and to the right the dorsal band was located. This band leads to the inner ileccecal fold which is situated medial to the cececolic fold, ileocecal junction and ileum. The small intestine was then traced craniad. The junction of the jejunum and duodenum was identified by locating the duodeno colic fold which runs from the terminal duodenum to the proximal small colon in the upper left quadrant. The duodenum can not be exteroized but was approached as it curves caudad toward and then around the mesocecal ligament to become attached to the right dorsal colon by duodeno-colicligament. The right

Assiut Vet.Med.1, Vol. 26, No. 52, January 1992. 


\section{SURGICAL ANATOMY OF THE ABDOMEN}

ventral ascending colon is conected to the cecum by the ceco-colic ligament. The four parts of ascending colon were distinguished by the number of bands. The pelvic flexure is usually to the left side. Both transveres colon and small colon can be explored by preceeding proximad and distad respectively from the deudenecolic fold. The transvetse colon is located just cranial to the cranial mesentric artery and is attached to the stomach by the gastrocolic ligament. The stomach, pylorus, spleen and liver were approached. The epiploic foramen is located in the right hypochon drinal region by first locating the pylorus and sigmoid flexrs of the duodenum. As one grasped the duodenum with the left hand and with the back of the hand against the caudate lobe of the liver the fingers will encounter the formamen. The roat of the liver the fingers will encounter the formamen. The roat of the small intestinal mesentry and cranial mesentric artery were aproached axial to the kidney. The uterus and urinary bladder can also be approached.

\section{Paramedian incission (Fig 6):}

The same exposed and explored abdominal and pelvic organs as that of the midline incision.

Inguinal incision (Fig 7):

By this incision the abdominal inguinal cryptorchid testicle can be exteriorised. Certain segments of the intestinal tract of the donkey along with ascending and descending colon can be aproached.

\section{DISCUSSION}

In the present work the anaesthesia used was that of local infiltration using procaine $\mathrm{HCl} 2 \%$ preceeded by comblen $10 . \mathrm{mg} / 100 \mathrm{~kg}$. B.W. I.M. for flank laparotomy in the standing position. The same anaesthesia was used for flank laparotomy be OEHME, et al. (1974). The ventral midline incision, inguinal incision and paramid line incision were done under the effect of chlorat hydrate narcosis $5 \mathrm{mg} / 50 \mathrm{~kg}$. B.W. $10 \%$ solution. I.V. Preceeded by comblene $10 \mathrm{mg} .10 \mathrm{~kg} . \mathrm{B} . \mathrm{W}$. i.m. While TURNER, et al. (1989), reported the used of general anaesthesia for these incisions in the horse.

\section{The surgical investigation showed that:}

\section{Venteral midline incision:}

The present work showed that this approach facilitates some operations as cesarean section,manipulation of the digestive organs,operations for severe colic volvulus, torsion or incarcerations of the intestine; gastrocuodenal obstruction in foals, intestinal intussusception, ovariectomies. removal of abdominal neoplasms, removal of urinary 
S.R. NOUH, et al.

calculi. These are in agreement with that reported by OEHME, et al. 1974; FRANK, 1982; STASHAK, et al. 1987 and TURNER, et al. 1989. While OEHME, et al. 1974 reported that the disadvantage of this approach lies in the danger of wound dehiscence, since the fibers of aponeurosis are not at right angles to the suture line.

\section{Paramid line approach:}

This approach does not allow as wide an exposure as the midine approach but it can be used for cesearian section, removal of cryptochid testicle,ovariectomy and exploratory operation. These results are in aggreement with that of OEHME, et al. (1974). This approach has the advantage that there is one danger of wound dehiscence as in ventral midline incison, so this approach is of greater safety and the large rectus muscle resists retraction but because of its tonus also prevents subsequent break down of the wound. This was not in agreement with that of STASHAK (1987) who reported that there was no advantage for this approach over the ventral midline incision.

\section{Flank approaches (right \& left):}

Our results showed that the flank incision can be used for operations as removing abdominally placed testicles, oophorectomies, exploratory palpation of the viscera. The right flank approach fascilitates, the examination of the base \& apex of the cecum, the ileocecal junction the middle portion of the right ventral colon, the right internal inguinal ring, the right kidney and right ovary. This approach can also be used in the management of uterine torsion and also for enterolith removal; this approach has no role in cases of severe colic in horse. These results agreed with that of OEHME, et al. (1974) and STASHAK (1987).

Inguinal approach. This approach is used for the removal of the cryptorchid testicles andinguinal hernial repair. The same results were reported by OEHME, et al. (1974); STASHAK, (1987) TURNER, et al. 1989.

\section{The abdominal closure:}

Closure for the different abdominal incisions were done on the same procedure reported by OEHME, et al. 1974; STASHAK, 1987 and TURNER, et al. 1989). In horses where theperitoneum was closed using catgut No. 0 the abdominal muscles \& subcutus with catgut No. 0 and linea alba in midline approach by catgut No. 0 then the skin was sutured by interrupted mattress pattern using silk No. 1.

Our results can conclude that the ventral midline approach is the approach of choice as it provides the simplest and quickest method for laparotomy in donkeys as it does not invade major vessels, nerves \& muscles.

Assiut Vet.Med.J., Vol. 26, No. 52, January 1992. 
SURGICAL ANATOMY OF THC ABDOMEN

\section{REFERENCES}

Delahunta, A. and Habel, R.E. (1986): Applied Veterinary Anatomy W.B. Saunderis Company, Philadelphia, London, Maxicocity. 1st Ed.

Dyce, K.M.; Sack, W.O. and Wensing, C.J.G. (1987): Textbook of Veterinary Anatomy. W.B. Saunder's Company. Harcourt Brace Jevanovich, Inc. Philadelphia, London, Torento. 1st Ed.

Frank, E.R. (1981): Veterinary Surgery C.Bs publishers \& Distributers Sharhdra Delhi. 1st Indian Ed.

Nickel, R.A. Schummer and E. Seiferle (1973): The Viscera of the domestic mammalse, Translation and revision by W.O. Sack 2 nd Ed.

Sisson, S. (1975): The Anatomy of the Domestic Animals. Equine digestive system. Volumel. (by Robert Getty) W.B. Saunders Company Philadaelphia, London. Toronto. 5th p. 454.

Stashak, T.S. (1987): Surgical Approaches, Anatomy of Abdominal Exploration and Andominal closure.

2nd Anuval Veterinary Surgical form, Europa, Proceedings for seminar No. 2 Equine General surgery Frank fsurt am main (West Germany) (61-64).

Turner, A-Simon, Mcilwraith, V. Wayne, Huli, Bruce. L. and MccRacken Tom (1989): Ventral Midline Laparotomy cryptorchidectomy bythe Nonivasive Inguinal Approach Lea \& Febiger. Philadelphia, London. 1st Ed.

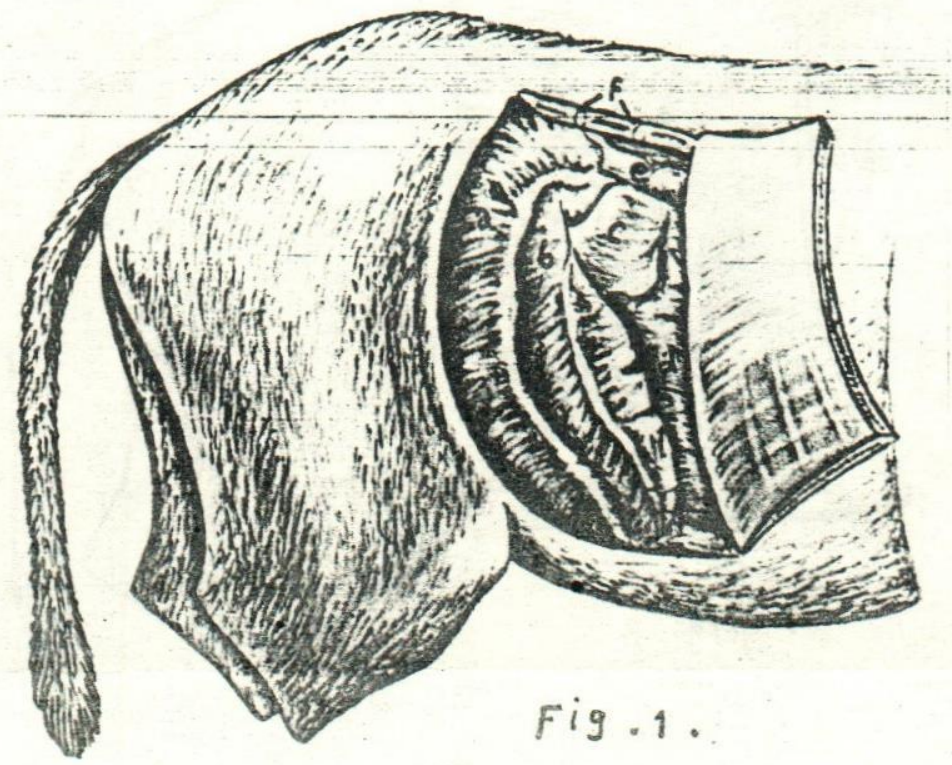


S.R. NOUH, et al.

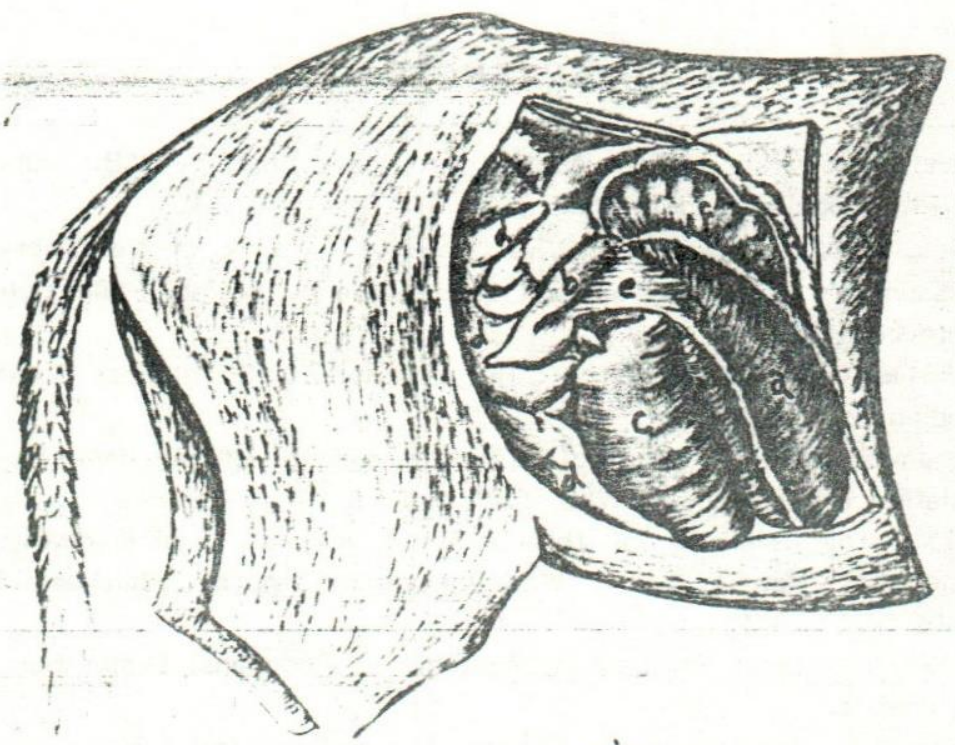

Fig. 2 .

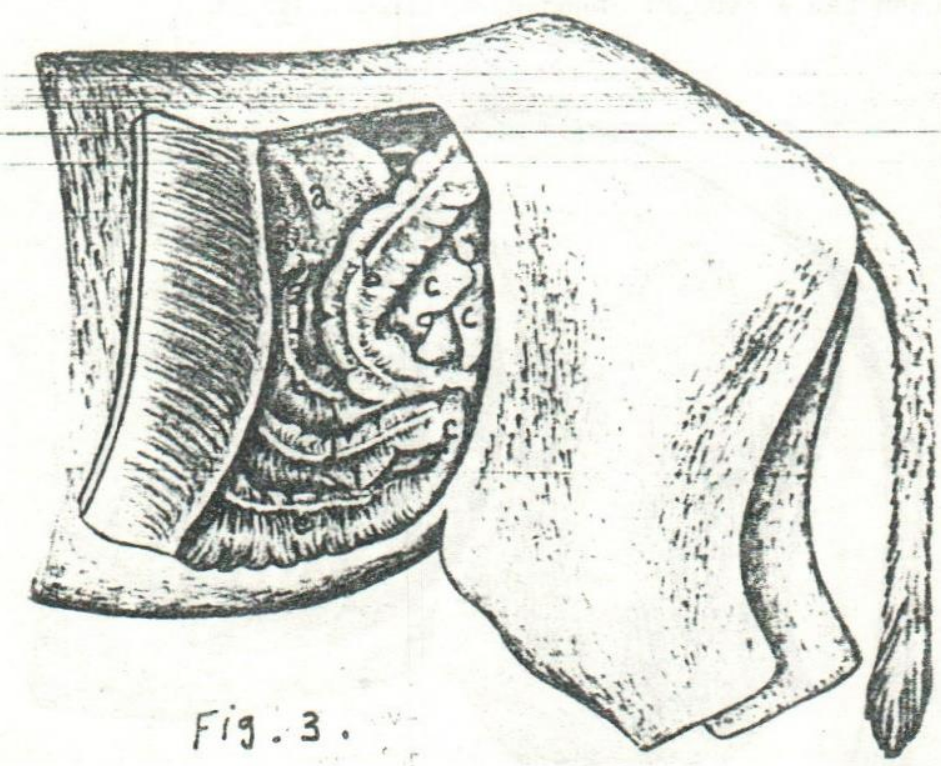

Assiut Vet.Med.J., Vol. 26, No. 52, January 1992. 
SURGICAL ANATOHYY OF THL ABDOMEN
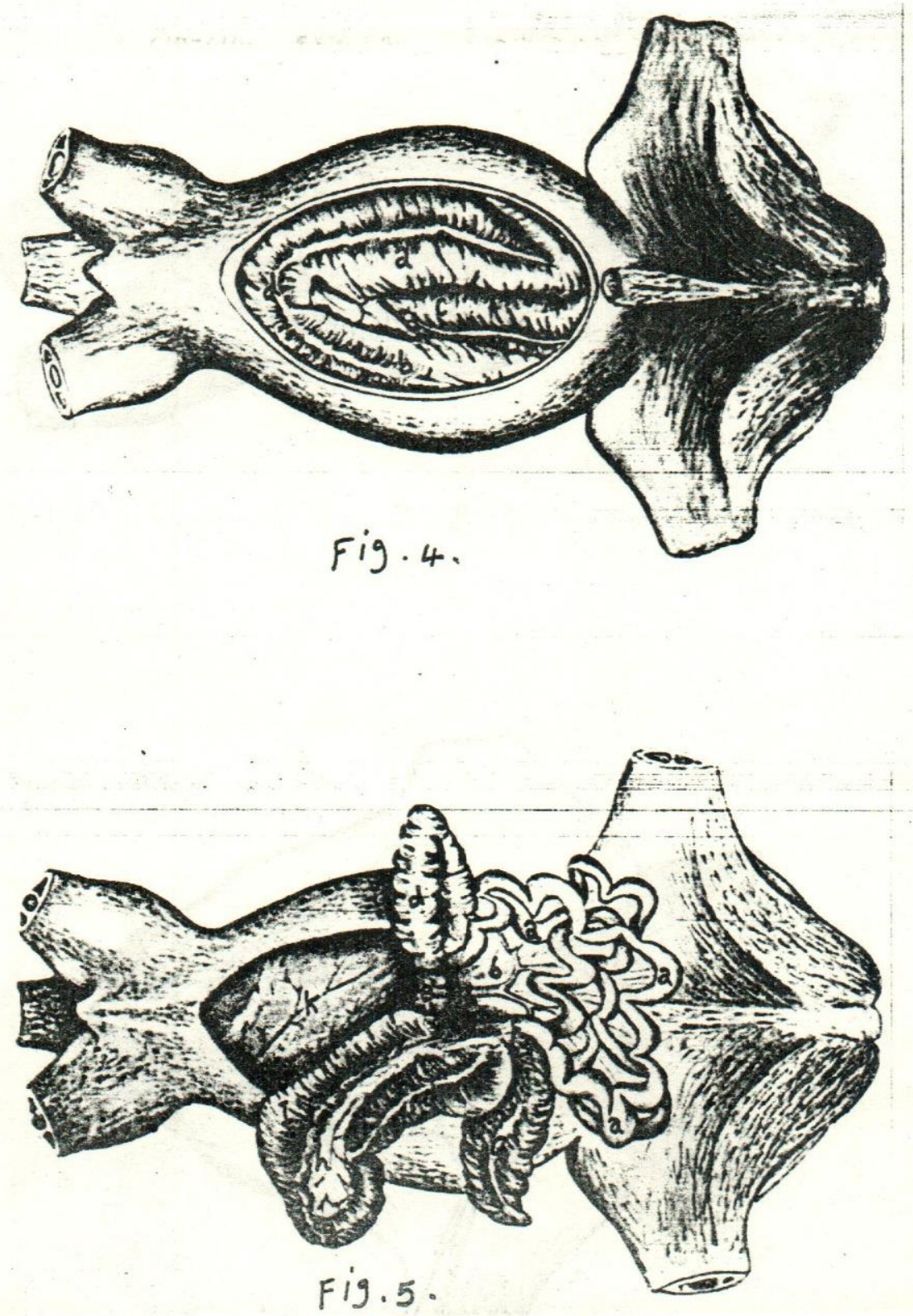
S.R. NOUH, et al.
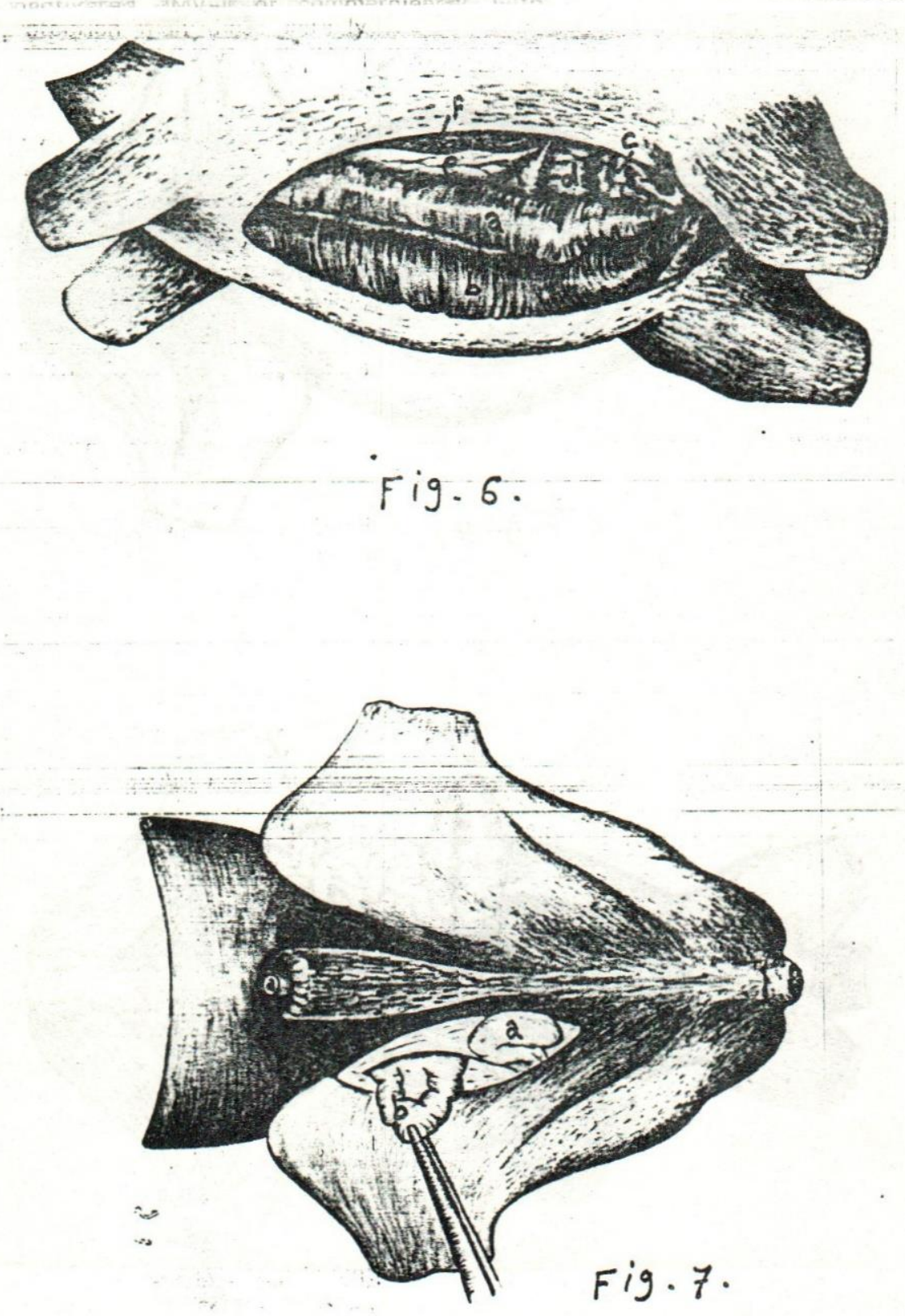

Assiut Vet.Med.1, Vol. 26, No. 52, January 1992. 